\title{
Role of Spironolactone Chalcone in the Prevention of Peritoneal Fibrosis in Patients with Peritoneal Dialysis
}

\author{
Liang Han ${ }^{1}$ and Xiao-Dong Yang ${ }^{2 *}$ \\ ${ }^{1}$ Department of Nephrology, ${ }^{2}$ Department of Endocrine, Zhumadian Center Hospital, Zhumadian 463000, China \\ *For correspondence: Email: yangxiaodong04@gmail.com; Tel/Fax: 0086-396-2726207
}

Received: 19 May 2015

Revised accepted: 29 August 2015

\begin{abstract}
Purpose: The study was designed to investigate the effects of a novel spironolactone chalcone in the prevention of peritoneal fibrosis.

Methods: Wistar rats $(n=30)$ were randomly assigned to 3 groups: bacteria $(B)$, spironolactone amide treatment $(S)$, and control $(C)$ groups. $C$ group received only dextran beads while $S$ and $B$ groups were given bacteria and dextran beads intraperitoneally, but spironolactone chalcone was also given to $S$ group. The treatments were administered daily. The rats were sacrificed on day 15 to quantify peritoneal adhesion and for histological examination of the peritoneal tissues using hematoxylin, eosin and Masson's trichrome dyes. Enzyme-linked immunosorbent assay (ELISA) kit was used to determine TGF 1 content of peritoneal fluids and serum samples.

Results: Spironolactone chalcone treatment at a dose of $30 \mathrm{mg} / \mathrm{kg}$ body weight daily for 15 days significantly reduced peritoneal total adhesion score in $S$ group compared to untreated $B$ group $(p<$ 0.01). S group also showed significantly lower mean peritoneal thickness, inflammation score, and fibrosis score compared to $B$ group. Serum transforming growth factor $\beta 1$ was also reduced significantly in $S$ group animals on spironolactone chalcone treatment compared to $B$ group.

Conclusion: Spironolactone chalcone is a potentially effective candidate for decreasing the extent of peritoneal injury caused by bacterial peritonitis.
\end{abstract}

Keywords: Peritoneal thickness, Inflammation score, Adhesion score, Bacterial peritonitis, Peritoneal fluids

Tropical Journal of Pharmaceutical Research is indexed by Science Citation Index (SciSearch), Scopus, International Pharmaceutical Abstract, Chemical Abstracts, Embase, Index Copernicus, EBSCO, African Index Medicus, JournalSeek, Journal Citation Reports/Science Edition, Directory of Open Access Journals (DOAJ), African Journal Online, Bioline International, Open-J-Gate and Pharmacy Abstracts

\section{INTRODUCTION}

Changes are induced in the peritoneal membrane due to the bio-incompatible components present in dialysis solution and frequent peritonitis episodes [1-4]. In peritoneal dialysis (PD) there is extracellular matrix accumulation, submesothelial fibrosis and decrease in ultrafiltration capacity [5].

Renin angiotensin aldosterone system in association with cytokine transforming growth factor $\beta$ is responsible for tissue repair [6-8]. It is reported that the peritoneal membrane damage is however prevented by angiotensin convertingenzyme inhibitors and angiotensin II receptor blockers [9-11]. There is improvement in prognosis of kidney injury patients using mineralocorticoid receptor antagonist [12,13]. PD complication, peritonitis [14] involves infective organism mediated inflammatory cytokines and interaction of resident cell populations of macrophages, mesothelial cells, and fibroblasts $[15,16]$. Increased submesothelial thickness, collagen deposition, increased cellularity, along with increased neovascularization in peritoneal 
tissue were observed in an inflammatory model after one week [17]. It is believed that growth factors and cytokines secreted by mesothelial cells, macrophages, and fibroblasts are associated with peritoneal fibrosis $[18,19]$.

Efforts have been made to prevent peritoneal fibrosis in PD patients using various drugs and chemicals to inhibit peritoneal mesothelial cell proliferation and/or matrix formation[20] [2124].

In the present study, the efficacy of spironolactone chalcone (Fig 1), an analogue of spironolactone in the prevention of peritoneal fibrosis in a rat experimental model of bacterial peritonitis was investigated.

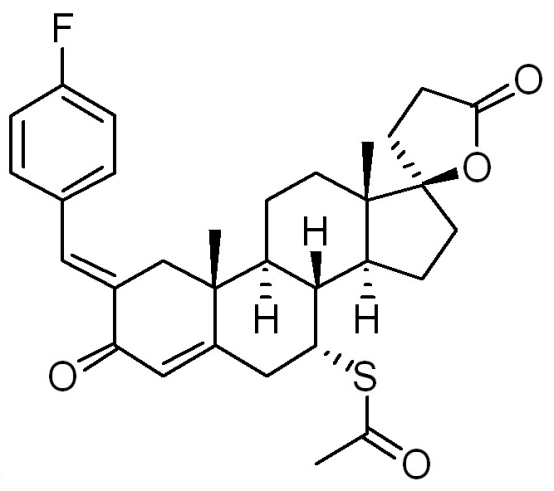

Fig 1: Structure of spironolactone chalcone

\section{EXPERIMENTAL}

\section{Animals}

A total of 30 male Wistar rats (aged, 8-10 weeks from the Animal Center of the Chinese Academy of Sciences, Shanghai, China) were housed in Animal house with a $12 \mathrm{~h}$ light/dark cycle. The study was approved by the Institutional Animal Committee of Shanghai University and in accordance with the Regulation for Animal Experiments of the University and Fundamental Guidelines for Proper Conduct of Animal Experiments and Related Activities in Academic Research Institutions under the jurisdication of the Ministry of Education, Culture, Sports, Science and Technology of China.

\section{Bacterial culture}

Fresh 6-9 h Staphylococcus aureus strain ATCC 25923 (American Type and Culture Collection, Rockville, Maryland, USA) cultures in a brainheart infusion broth (Oxoid, Basingstoke, UK) were prepared in an agitated water bath at 37 ${ }^{\circ} \mathrm{C}$. To determine the actual inoculum sizes serial dilutions were prepared. Dextran beads (Cytodex; Sigma Chemicals, St Louis, Missouri, USA) were added to the bacterial suspensions for easier inoculation into the peritoneum.

\section{Experimental procedures}

Thirty rats were randomly assigned into 3 groups of 10 each: bacteria (B), bacteria + spironolactone chalcone (S), and control (C) groups. Rats in $B$ and $S$ groups were intraperitoneally given bacteria mixed with dextran beads whereas the Group $C$ received only dextran beads via a $1 \mathrm{~mL}$ tuberculin syringe. Spironolactone chalcone at a dose of $30 \mathrm{mg} / \mathrm{kg}$ body weight was given daily to group $S$ rats for 15 days via an oro-gastric tube.

On 15th day after ketamine anesthesia treatment peritoneal fluid was collected from the rat peritoneal cavity. The fluid was centrifuged $\left(4^{\circ} \mathrm{C}\right.$, $12000 \mathrm{rpm}$ for $20 \mathrm{~min}$ ) to remove insoluble particles and the supernatants were stored at -50 ${ }^{\circ} \mathrm{C}$. Then laparotomy was performed and the gross adhesion scoring system was used to assess the extent of peritoneal adhesion. Three $\mathrm{mL}$ blood samples were collected from the vena cava caudalis and serum samples were stored at $-50{ }^{\circ} \mathrm{C}$. After sacrifice peritoneum, liver, small intestine, and abdominal wall tissue samples were taken from the injection site.

\section{Morphological and histological analysis of the peritoneal cavity}

For evaluation of peritoneal adhesion score, most prominent adhesion sites which include site between the liver and omentum, omentum and intestinal wall, intestine and the abdominal wall, and intestine and the stomach were selected. Complete absence of adhesion was assigned a zero score; 1 to 3 separate adhesions a score of 1 and 3 indicate distinctly separate adhesions while a score of 2 denote diffuse sheet-like adhesions.

\section{Histological analysis}

The formalin fixed and paraffin-embedded tissues samples together with peritoneum were cut into $2 \mathrm{~mm}$ thick slices and stained with hematoxylin \& eosin and Masson's trichrome dyes. After deparafinization the sections were examined under light microscope. Absence of inflammation was assigned score 0 ; mild inflammation score 1; moderate inflammation score 2; and severe inflammation score 3. The presence of fibrosis was evaluated semiquantitatively from Masson's trichromestained sections: score 0 , small scattered areas 
of green staining; score 1, thin bands of green staining; score 2, thicker, connected bands of green staining; score 3, thick and dense areas of green staining.

\section{Chemical analysis}

Enzyme-linked immunosorbent assay kit (Promega, Madison, Wisconsin, USA) was used to determine the content of TGF- $\beta 1$ in peritoneal and serum samples.

\section{Statistical analysis}

The results are expressed as mean \pm SD. SPSS 11.0 software (SPSS Inc, Chicago, Illinois, USA) was used for statistical analysis, Kruskal-Wallis test for continuous variables, and Mann-Whitney test with Bonferroni correction; the later was used for post hoc analysis. Spearman's rank test was used for correlation among the parameters. Differences were considered statistically significant at $p<0.05$.

\section{RESULTS}

\section{Peritoneal adhesion scoring system}

The semi quantitative analysis of total peritoneal adhesion score revealed a zero score in the control group. However the total peritoneal adhesion score was significantly higher in the $B$ group (4.54 \pm 1.03$)$ compared to that in the control group (0). The score for the $S$ group was close to that of the control group $(0.34 \pm 0.02)$.

\section{Histological analysis}

The examination of peritoneal thickness of three different sites showed that the liver surface thickness (Fig 2) was significantly lower in the $S$ $(2.21 \pm 0.41 \mathrm{~mm})$ and $\mathrm{C}(1.87 \pm 0.35 \mathrm{~mm})$ groups compared to that of the B group (402.37 \pm $301.87 \mathrm{~mm}$ ). Mean peritoneal thickness of intestinal wall was lower in the treatment $S$ group $(14.18 \pm 2.78 \mathrm{~mm})$ than in the B group (911.36 \pm
$298.46 \mathrm{~mm}$ ). In control group the level of peritoneal thickness was significantly lower $(12.23 \pm 2.67 \mathrm{~mm})$. The examination of the mean peritoneal thickness of abdominal wall also showed lower thickness of the $S$ group (37.23 \pm $2.98 \mathrm{~mm}$ ) compared to that in the $B$ group $(184.87 \pm 73.43 \mathrm{~mm})$. It was significantly lower only in the control group (32.76 $\pm 2.82 \mathrm{~mm})$ compared to the B group $(p<0.05)$.

Analysis of the data from three peritoneal locations showed that the values for mean peritoneal inflammation, mean peritoneal fibrosis, and mean peritoneal thickness were significantly higher in the B group compared to the control group. The values of mean peritoneal inflammation in the $\mathrm{B}, \mathrm{S}$ and $\mathrm{C}$ groups were 2.04 $\pm 0.65,0.13 \pm 0.03$ and $0.10 \pm 0.01$ respectively. The values of mean peritoneal fibrosis were 2.34 $\pm 0.71,0.48 \pm 0.12$ and $0.34 \pm 0.10$ whereas the values of mean peritoneal thickness were 502.23 $\pm 159.93,15.34 \pm 43$ and $13.67 \pm 1.86 \mathrm{~mm}$ in the $\mathrm{B}, \mathrm{S}$ and $\mathrm{C}$ groups respectively $(p<0.05)$. Mean peritoneal thicknesses in all groups are shown in Fig 3.

\section{Chemical composition}

Analysis of the level of TGF $\beta 1$ in peritoneal washing fluid and serum of the rats from the $B, S$ and $C$ group showed that the level was significantly higher in B group compared to that in the $C$ group. However the level of TGF $\beta 1$ in both the peritoneal washing fluid and serum in the $S$ group was close to that of the $C$ group (Table 1).

Table 1: The level of mean transforming growth factor $\beta 1$ (TGF $\beta 1$ ) in peritoneal washing fluids and serum

\begin{tabular}{lcc}
\hline \multirow{2}{*}{ Group } & \multicolumn{2}{c}{ TGF $\beta 1(\mathrm{ng} / \mathbf{m L})$} \\
\cline { 2 - 3 } & $\begin{array}{c}\text { Peritoneal } \\
\text { washing }\end{array}$ & Serum \\
\hline Bacteria (B) & $5.69 \pm 0.87$ & $60.32 \pm 5.34$ \\
Spironolactone (S) & $2.32 \pm 1.36$ & $19.45 \pm 4.03$ \\
Control (C) & $1.98 \pm 0.12$ & $16.55 \pm 1.86$ \\
\hline
\end{tabular}

Bacterial Group (B)

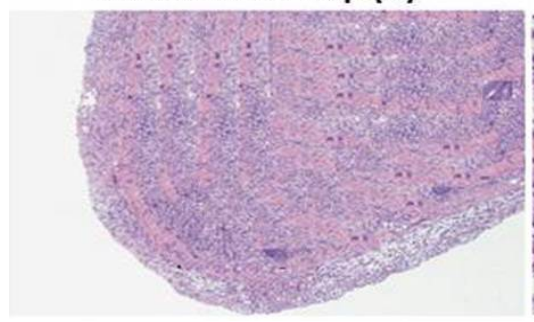

Treatment group (S)

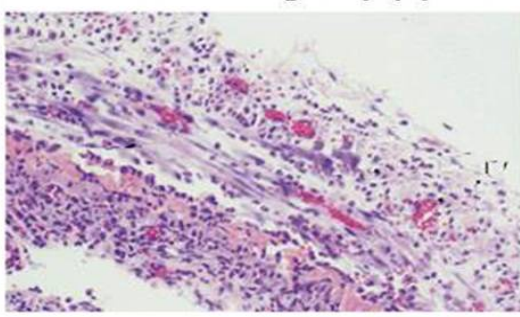

Control group (C)

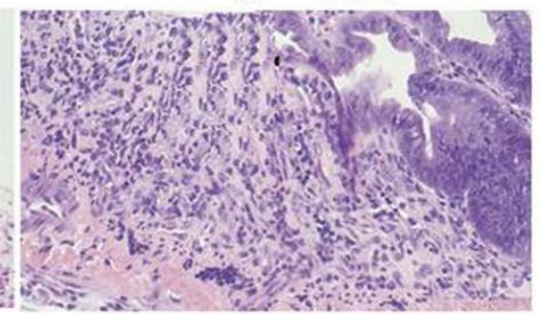

Fig 2: Masson's trichrome-stained peritoneum sections demonstrate fibrotic thickening between the mesothelium and the liver surface in the B (bacterial), S (spironolactone chalcone) and C groups (control) 


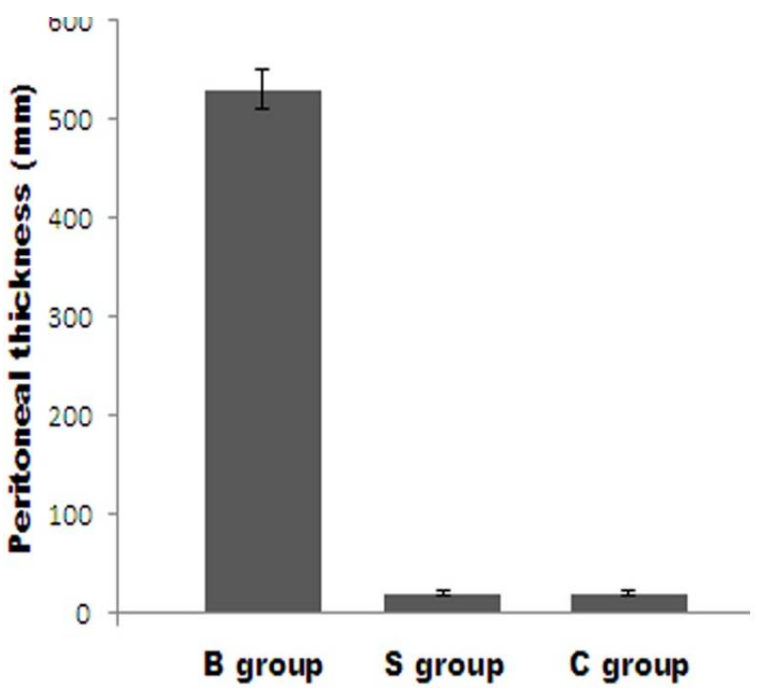

Fig 3: Mean peritoneal thickness in the $B$ (bacterial), $S$ (spironolactone chalcone) and $\mathrm{C}$ (control) groups

\section{DISCUSSION}

In PD patients, the episodes of peritonitis are the major cause which leads to peritoneal fibrosis. In our study, a rat model of Staphylococci induced peritoneal fibrosis and vehicle enhanced peritonitis was used to investigate the effect of spironolactone chalcone on peritoneal fibrosis. The results revealed absence of peritoneal adhesion scores in the control group whereas the score in B group was significantly higher. Treatment of the rats with spironolactone chalcone resulted in a significant decrease in peritoneal adhesion scores and the score was close to that of the control group. This demonstrates the potential of spironolactone chalcone in preventing the effects of peritonitis.

We observed that mean peritoneal thickness in the B group was significantly higher compared to control group, suggesting the efficacy of the experimental model in damaging the peritoneal membrane. Additionally, the lower peritoneal adhesion scores and thinner peritoneum in rats given spironolactone chalcone than those of the $\mathrm{B}$ group demonstrate that these drugs were able to limit peritoneal injury due to acute bacterial peritonitis. In spironolactone chalcone treatment group the mean peritoneal thickness was significantly lower compared to that of the bacterial group.

The analysis of individual peritoneal sites showed a lower peritoneal thickness in the treatment group than in the bacterial group. Comparison of the mean fibrosis and inflammation scores revealed similar and higher scores in the treatment and control group compared to that of the control group. Our study shows that the spironolactone amide used was able to limit peritoneal damage due to bacterial peritonitis. Our results from the analysis of TGF $\beta 1$ level in peritoneal washing fluid and serum of the rats demonstrated that the levels of TGF $\beta 1$ were significantly decreased on spironolactone chalcone treatment compared to that in untreated bacterial group. Enhanced level of TGF $\beta 1$ in the rat serum is a clear indication of response to peritonitis.

\section{CONCLUSION}

Histopathological data demonstrate that spironolactone amide decreases peritoneal injury due to bacterial peritonitis. Therefore, spironolactone amide may be useful in the prevention of peritoneal injury suffering peritonitis in peritoneal dialysis patients.

\section{REFERENCES}

1. Davies SJ. Longitudinal relationship between solute transport and ultra-filtration capacity in peritoneal dialysis patients. Kidney Int 2004; 66: 2437-2445.

2. Flessner MF. The transport barrier in intraperitoneal therapy. Am J Physiol Renal Physiol 2005; 288: F433442.

3. Mateijsen MA, Van der Wal AC, Hendriks PM. Vascular and interstitial changes in the peritoneum of CAPD patients with peritoneal sclerosis. Perit Dial Int 1999; 19: 517-525.

4. Davies SJ, Bryan J, Phillips L, Russell GI. Longitudinal changes in peritoneal kinetics: the effects of peritoneal dialysis and peritonitis. Nephrol Dial Transplant 1996; 11: 498-506.

5. Williams JD, Craig KJ, Topley N. Morphologic changes in the peritoneal membrane of patients with renal disease. J Am Soc Nephrol 2002; 13: 470-479.

6. Border WA, Noble NA. Transforming growth factor beta in tissue fibrosis. N Engl J Med 1994; 331: 1286-1292.

7. Garosi G, Di Paolo N, Sacchi G, Gaggiotti E. Sclerosing peritonitis: a nosological entity. Perit Dial Int 2005; 25(supp/3): S110-12.

8. Margetts PJ, Kolb M, Galt T, Hoff CM, Shockley TR, Gauldie J. Gene transfer of transforming growth factorbeta1 to the rat peritoneum: effects on membrane function. J Am Soc Nephrol 2001; 12: 2029-2039.

9. Duman S, Günal Al, Sen $S$. Does enalapril prevent peritoneal fibrosis induced by hypertonic (3.86\%) peritoneal dialysis solution? Perit Dial Int 2001; 21 : 219 224.

10. Duman S, Sen S, Duman C, Oreopoulos DG. Effect of valsartan versus lisinopril on peritoneal sclerosis in rats. Int J Artif Organs 2005; 28: 156-163.

11. Sauter M, Cohen CD, Wörnle M, Mussack T, Ladurner R, Sitter T. ACE inhibitor and AT1-receptor blocker

Trop J Pharm Res, October 2015; 14(10): 1896 
attenuate the production of VEGF in mesothelial cells. Perit Dial Int 2007; 27: 167-172.

12. Pitt B, Remme W, Zannad F. on behalf of the Eplerenone Post-Acute Myocardial Infarction Heart Failure Efficacy and Survival Study investigators. Eplerenone, a selective aldosterone blocker, in patients with left ventricular dysfunction after myocardial infarction. N Engl J Med 2003; 348: 1309-1321.

13. Pitt B, Zannad F, Remme WJ. The effect of spironolactone on morbidity and mortality in patients with severe heart failure. Randomized Aldactone Evaluation Study investigators. N Engl J Med 1999; 341: 709-717.

14. Bunke CM, Brier ME, Golper TA. Outcomes of single organism peritonitis in peritoneal dialysis: gram negatives versus gram positives in the Network 9 Peritonitis Study. Kidney Int 1997; 52: 524-529.

15. Topley $N$, Liberek T, Davenport A, Li FK, Fear $H$, Williams JD. Activation of inflammation and leukocyte recruitment into the peritoneal cavity. Kidney Int Suppl 1996; 56: S17-21.

16. Jorres A, Ludat K, Sander K, Dunkel K, Lorenz F, Keck $H I$. The peritoneal fibroblast and the control of peritoneal inflammation. Kidney Int Suppl 1996; 56: S22-27.

17. Margetts PJ, Kolb M, Yu L, Hoff CM, Holmes CJ, Anthony $D C$. Inflammatory cytokines, angiogenesis, and fibrosis in the rat peritoneum. Am J Pathol 2002; 160: 22852294.

18. Beavis MJ, Williams JD, Hoppe J, Topley N. Human peritoneal fibroblast proliferation in 3-dimensional culture: modulation by cytokines, growth factors and peritoneal dialysis effluent. Kidney Int 1997; 51: 205-15.

19. Jorres A, Ludat K, Lang J, Sander K, Gahl GM, Frei U. Establishment and functional characterization of human peritoneal fibroblasts in culture: regulation of interleukin6 by proinflammatory cytokines. J Am Soc Nephrol 1996; 7: 2192-2201.

20. Gambaro G, Weigert C, Ceol M, Schleicher ED. Inhibition of transforming growth factor-b1 gene overexpression as a strategy to prevent fibrosis. Contrib Nephrol 2001; 131: 107-113.

21. Fracasso A, Baggio B, Ossi E, Del Prete D, Bonfante $L$, Bazzato G. Glycosaminoglycans prevent the functional and morphological peritoneal derangement in an experimental model of peritoneal fibrosis. Am J Kidney Dis 1999; 33: 105-110.

22. Hung $K Y$, Shyu RS, Fang CC. Dipyridamole inhibits human peritoneal mesothelial cell proliferation in vitro and attenuates rat peritoneal fibrosis in vivo. Kidney Int 2001; 59: 2316-2324.

23. Duman S, Günal Al, Sen S, Asci G. Does enalapril prevent peritoneal fibrosis induced by hypertonic (3.86\%) peritoneal dialysis solution? Perit Dial Int 2000; 21:219-224.

24. Duman S, Sen S, Duman C, Oreopoulos DG. Effect of lisinopril versus valsartan on peritoneal alterations in rats. Int J Artif Organs 2005; 28:156-163.

25. Coronel F, Berni A, Cigarran S, Calvo N, Herrero JA. Effects of angiotensin II receptor blocker (irbesartan) on peritoneal membrane functions. Adv Perit Dial 2004; 20: 27-30. 